\title{
Formação de professores de Biologia e a leitura semiológica de cartuns da Revista Ciência Hoje das Crianças
}

Biology training teachers and semiological analysis of cartoon published by Ciência Hoje das Crianças Journal

\author{
Paulo Cesar Gomes ${ }^{1}$ \\ Alexandra Bujokas de Siqueira ${ }^{2}$
}

\section{Resumo}

A formação de professores no Brasil vem passando por contínuas e complexas transformações e têm, cada vez mais, exigido posturas atreladas ao nosso tempo. Formar jovens professores para que compreendam mensagens - de quaisquer naturezas - de forma crítica está previsto, enquanto competência profissional, em documento internacional da UNESCO, contudo, o desenvolvimento desta, remete a uma reestruturação curricular nos cursos de licenciatura em todo o país. Os cursos de licenciatura tem repertório docente para a compreensão de competências voltadas à Alfabetização Midiática e Informacional (AMI), como proposto pela UNESCO? Nossos objetivos neste trabalho de pesquisa foram: (a) investigar e apresentar concepções de professores em formação acerca de um cartum publicado em suplemento da Revista Ciência Hoje das Crianças voltado ao público infantojuvenil e (b) apresentar uma análise semiológica estrutural de elementos imagéticos constante do mesmo cartum a partir do referencial teórico barthesiano. Os resultados sugerem que: (a) licenciados e licenciandos realizaram, em sua maioria, uma leitura sem profundidade do cartum apresentado; (b) o cartum, de modo geral, realiza por si mesmo uma "leitura de sociedade" tal qual a visão do autor que o produziu.

Palavras-chaves: semiologia; imagem; cartum.

\section{Abstract}

Teacher training in Brazil has been undergoing continuous and complex transformations, which I have increasingly required attitudes according to our time. It is necessary to train people to critically understand messages - of any nature - as proclaimed by the UNESCO international document with professional competence. However, this development requires changes to a curricular restructuring in undergraduate courses in Brazil. Do the undergraduate courses have teaching repertoires for the understanding of competences related to Media Literacy and Information Literacy (AMI), as proposed by UNESCO? Our objectives in this research were: (a) to investigate and present conceptions of teachers in formation about a cartoon published in a supplement to the journal Science Today of Children aimed at children and adolescents and (b) to present a semiological structural analysis of imaging elements constant of the same cartoon from the barthesian theoretical reference. The results suggest

\footnotetext{
${ }^{1}$ Universidade Estadual Paulista Júlio de Mesquita Filho | pcgomes21@gmail.com

2 Universidade Federal do Triângulo Mineiro | alexandra.bujokas@midia-educacao.net
} 
that: (1) licensees and undergraduates mostly performed a non-depth reading of the presented cartoon; (2) the cartoon, in general, performs for itself a "society reading" just like the author who produced it. It is vital to understand the way in which these people shape a particular society's reading of cartoon.

Keywords: semiology; image; cartoon.

\section{Introdução}

A Educação Brasileira sofreu nas últimas décadas consideráveis transformações, estas têm exigido propostas consistentes de formação inicial e continuada de professores, especialmente no desenvolvimento profissional da docência (LEAL, REALI, 2015). As reformas na Educação Brasileira ganharam ênfase a partir da aprovação da Lei de Diretrizes e Bases da Educação Nacional (LDBEN - Lei 9.394/96), do lançamento dos Parâmetros Curriculares Nacionais (PCN) e, mais recentemente, pela aprovação da Base Nacional Curricular Comum (BNCC, 2017). Estas e outras legislações têm destacado a importância de investimentos na formação de professores e também em políticas de reestruturação de todo o Sistema Educacional Brasileiro, mudanças exigidas por contínuas transformações científicas e tecnológicas e que tem demandado necessidades formativas distintas dos profissionais da Educação. Os processos de formação de professores têm considerado a revisão de conteúdos e de metodologias utilizada em sala de aula de modo a objetivar processos críticos-reflexivos sobre a prática educativa (BNCC, 2017; MEC, 1998a; 1998b) na formação do outro. Da mesma maneira, a constante exigência de melhorias na qualidade na Educação Básica remete ao desenvolvimento de uma prática profissional no magistério que esteja comprometida com processos educativos que visem formar pessoas (mais) críticas, de forma a exercitar sua cidadania, além de compreender a forma como interpretam e são impactados pelas diferentes mídias. Sabe-se que existem inúmeros desafios às políticas públicas de formação continuada de professores, bem como à produção de conhecimentos na área da formação profissional de professores. No que concerne à formação docente, também se faz necessário ampliar, no contexto da formação inicial, o repertório docente para a compreensão de competências voltadas à Alfabetização Midiática e Informacional (AMI), como proposta pela UNESCO $^{3}$ (2013). Dito de outro modo, é preciso compreender o que os professores devem saber e saber fazer para que seus estudantes reflitam, de forma crítica e não dogmática, sobre questões: (i) Como as diferentes pessoas compreendem as diversas mensagens veiculadas pelas mídias e por que o fazem desta forma? (ii) É possível, no âmbito da sala de aula, desconstruir estereótipos e preconceitos (étnicos, de gênero, sexistas e contra minorias) decorrentes das relações de poder historicamente construídas e também existentes em torno da chamada cultura midiática? (iii) Existem outras leituras dos textos midiáticos quando se trata do seu uso complementar (por exemplo, de um veiculo de comunicação de massa) na sala de aula de ciências? (iv) Por fim, possibilitar a compreensão e o desvelamento de questões constantes (não somente) na cultura midiática e, sobretudo, incentivar a seleção, produção e divulgação de ideias também não contribuem para o pleno exercício da cidadania e da liberdade de expressão dos nossos jovens?

Na formação de professores de ciências existem diferentes lacunas, como bem apontaram Carvalho e Gil-Pérez (2001). Neste sentido, questionamos: estaria o professor de

\footnotetext{
${ }^{3}$ Disponível em: http://unesdoc.unesco.org/images/0022/002204/220418por.pdf. Acesso em 06/02/2018.
} 
ciências preparando adequadamente seus estudantes para uma compreensão crítica dos conteúdos veiculados pelas diferentes mídias? O domínio de conhecimentos desta natureza, permitiria segundo o documento sobre Alfabetização Midiática e Informacional (AMI), da UNESCO (2013), o acesso à informação de forma engajada e significativa, de forma que, "As competências adquiridas pela alfabetização midiática e informacional podem equipar os cidadãos com habilidades de raciocínio crítico, permitindo que eles demandem serviços de alta qualidade das mídias e de outros provedores de informação" (UNESCO, 2013, p.16, grifos nossos), tornando-os aptos a demandarem uma maior qualidade das mídias e de seus provedores. As competências elencadas no documento da UNESCO não se desenvolvem nas pessoas pelo mero acesso a elas e, tampouco pelo excessivo contato com o texto midiático pelo jovem adolescente e, assim, "é pouco provável que tenha habilidades para identificar, analisar e refletir sobre os processos que usa para atribuir sentido às mensagens midiáticas, considerando as características do contexto social onde elas são geradas" (SIQUEIRA, 2014, p.64, grifos nossos). Diante do exposto, estima-se importante uma investigação acerca de como graduandos e graduados num curso de Licenciatura em Ciências Biológicas realizam leituras de um cartum de uma revista de divulgação científica, isto é, realizam análises de imagens que ilustram os textos de divulgação científica comumente utilizados em salas de aulas de ciências e biologia. Ressalta-se que o texto da Base Nacional Curricular Comum (BNCC, 2017) define dentre outras competências do ensino de ciências que o estudante acolha e valorize a diversidade de indivíduos e grupos sociais, rechaçando preconceitos de quaisquer naturezas, de forma "Utilizar diferentes linguagens e tecnologias digitais de informação e comunicação para se comunicar, acessar e disseminar informações, produzir conhecimentos e resolver problemas das Ciências da Natureza de forma crítica, significativa, reflexiva e ética" (BNCC, 2017, p 332, grifo meu).

Vale destacar que nosso interesse na realização deste trabalho, enquanto proposta de pesquisa, iniciou-se com a leitura dos trabalhos de Campos et al $(2009,2009 a, 2008)$ sobre a análise semiológica de cartuns em uma campanha de ônibus na cidade de Belo Horizonte, no estado de Minas Gerais, Brasil. Desde os primeiros anos escolares, a inserção e prevalência de determinados tipos de imagens humanas - fotos, desenhos, vídeos, cartuns, etc. - em materiais didáticos e paradidáticos da nossa Educação Escolar foi algo que sempre incomodou-nos, mas sem uma razão definida ao olhar (até ingênuo) de estudante do Ensino Fundamental. Hoje sabemos que esta inquietação ocorria justamente pela não representatividade da população brasileira em sua plenitude ou de seus muitos "recortes de sociedade", isto é, dos papéis socialmente assumidos por mulheres e homens, da exclusão de idosos, adolescentes e crianças, e até mesmo das diferenças entre as classes sociais brasileiras "excluídas" da foto, sobretudo da falta de diversidade étnica e cultural ou da chamada brasilidade. Alguns autores têm chamado este fenômeno de apagamento étnico ou social (NASCIMENTO, 2016; OLIVEIRA NEVES, 2012; COELHO DE SOUZA, 2010; SANTOS, 2001). Esta noção e ideia de leitura de mídia estão inseridas nos trabalhos denominados Letramentos Sociais do autor Street (2014) que amplia a noção de letramento como vinha sendo propagada desde a década de 1990. Esta noção também permite crer que exista uma Educação que permita a compreensão da realidade vivida e exibida nos Media.

Todos sabem ler imagens? Isto é, fotografias, cartuns, infográficos, gráficos, mapas, tabelas e quadros? Afinal o mundo contemporâneo vive um momento paradigmático, pois de um lado, tem sido alvo do chamado Ocularcentrismo, no qual o cidadão médio tem sido constantemente vigiado por câmeras, leitores de impressão digital e muito mais que "viver o 
momento" ou "atuar de forma contemplativa" é imortalizá-lo na forma de fotografias ou vídeos. De outro lado, a grande massa da população (que não é mais tão ingênua quanto nos anos 1950) vive e convive com o Analfabetismo Visual (BANKS, 2009; ROSE, 2002).

\section{A Revista Ciência Hoje das Crianças}

A Revista Ciência Hoje das Crianças, doravante, CHC, é um veículo de comunicação de massa e de divulgação científica que teve origem em plena "ditadura brasileira" ou "governo militar" em meados da década de 1980. A CHC é produzida pela Sociedade Brasileira para o Progresso da Ciência (SBPC) e desde o início busca atingir o público jovem, especialmente, crianças e adolescentes na divulgação da Ciência, contudo aborda temas como costumes brasileiros, história, literatura e outros (CORREA, 2015; GOUVÊA, 2005; 2000; MASSARANI, 1999). A CHC é bem colorida com fotos e ilustrações, dentre estas, inúmeros cartuns. A revista publicou em seu sítio da internet que seu objetivo é "despertar a curiosidade de meninos e meninas" (CHC on line, em web: http://chc.org.br/sobre-a-chc). O website, em linguagem jovem e "descolada", informa também que a CHC foi a primeira revista do Brasil que é voltada para crianças, que já ganhou o prêmio José Reis de Divulgação Científica e que sua distribuição alcança bibliotecas de mais de sessenta mil escolas em todo o território nacional brasileiro. Além das revistas em papel e website servirem como fontes de busca para estudantes e professores, a revista tem investido em outras fontes de divulgação dos textos e imagens produzidas na forma de livros e programas de TV.

\section{O Cartum e a Fotografia em Roland Barthes}

Antes de tratar propriamente da Semiologia, é preciso esclarecer o que compreendemos como cartum e nossas analogias deste com a Fotografia. O cartum é compreendido como um gênero textual elaborado mormente por linguagem não-verbal, contudo pode conter linguagem verbal, geralmente, produzido pelos produtores de comunicação (PEREIRA, 2015). Trata-se, segundo este autor, de discursos produzidos a partir de representações do "imaginário coletivo" ou extraídos diretamente do "mundo concreto". O cartum é gênero cujos signos são de fácil decodificação o qual pode (icônico) ou não (icônico verbal) estar associado a um texto escrito. Os cartuns são produzidos para uma dada audiência e que suas análises demandam conhecimento do contexto de produção - do cartunista, no caso, parâmetro físico da linguagem em curso e inserção espaço-temporal (BRONCKART, 1999 apud PEREIRA, 2015). De outro modo, suas análises demandam a compreensão das relações existentes entre o seu contexto de produção, interlocução e espaço-tempo de produção. Shaw (2007) e Olímpio (2013) alegaram que os cartuns surgiram nos Estados Unidos no século dezoito e preconizavam inicialmente assuntos políticos. Segundo eles, os cartuns tem estrutura pautada em estereótipos e símbolos comuns e têm muito a oferecer a pesquisa social porque tratam que aspectos peculiares da vida política, individual e cultural, de forma a revelar medos, visões de mundo, preconceitos e, por fim, seus pressupostos. A nosso ver as imagens publicadas na Revista Ciência Hoje das Crianças e seus suplementos são cartuns porque se tratam de elaborações atuais que representam o dia-a-dia e determinado momento de intervenção, utilizam o exagero, a estilização caricatural e a deformação enquanto concepção cujo objetivo central é ridicularizar e criticar a sociedade (OLIMPIO, 
2013). Para Barbosa e Rabaça (1998), em seu Dicionário de Comunicação, um Cartum é uma anedota gráfica. Neste sentido, um cartum, no seu sentido clássico ou tradicional é entendido como "jogo visual de ideias contido numa única ilustração, sem a presença de qualquer texto escrito. No entanto, há cartuns que se utilizam de balões ou legendas, outros que apresentam duas ou mais ilustrações em sequência (XAVIER, 2001, p.196). Diferentemente das propostas de definição de cartum acima apresentadas, os cartuns, em especial, os publicados pela Revista Ciência Hoje das Crianças, nem sempre contêm o traço humorístico e anedótico mencionados nos dicionários e, talvez nem sempre satirize os comportamentos humanos. Contudo, dialogam com seus títulos e com os textos de divulgação científica no veículo de comunicação de massa aqui considerado. A nosso ver, os cartuns mantêm contínuo diálogo com a sociedade contemporânea e são interpretados a luz dos valores morais vigentes, de acordo com seus aspectos intrínsecos à obra, sejam eles locais, regionais, políticos e/ou históricos. Quais aproximações são possíveis entre o Cartum e a Fotografia?

A tentativa de classificar os cartuns assemelha-se, segundo Gillian Rose (2002), e dada as devidas proporções, à classificação da Foto, como proposta por Barthes $(2015 ; 2009)$ e mesmo por Sontag (2004): assim como a Fotografia, "eles coalham". São inclassificáveis também? A que os temas remetem? Quem foi representado e quem não foi? Quais os sentidos atribuídos pelo leitor e quais leituras são feitas dos cartuns publicados adjacentes aos texto de divulgação científica? Assim como a Fotografia, o Cartum está ligado ao seu referente (aquilo que é representado), deste modo, assim como a foto de uma crisálida remete a uma crisálida real, a representação cartunizada deste mesmo ser vivo também remete ao ser vivo real (usando, por analogia, um exemplo de Barthes). Talvez este mundo real, esteja mais entranhado na Fotografia do que no Cartum, neste sentido, "privadas de um princípio de marcação, as fotos são signos que não prosperam bem, que coalham, como leite. Seja o que for o que ela dê a ver e qualquer que seja a maneira, uma foto é sempre invisível: não é ela que vemos" (BARTHES, 2015, p.15).

As semelhanças não se restringem a este aspecto. O sítio de produção do cartum [cartunista - Operator, fotógrafo, a produção de enquadramentos e suas omissões], sítio de divulgação [galerias, museu, revistas, sites da internet, redes sociais, álbum de família, etc.], o alvo da representação no cartum ou o objeto/pessoa/paisagem fotografada [o real representado no cartum ou seu Spectrum], sítio da audiência [leitor ou quem consome as imagens ou Spectator]. Outros paralelismos entre a Fotografia e o Cartum também podem existir se considerarmos uma matriz Barthesiana. Na relação entre o Spectator e o Cartum, os interesses de quem olha para os cartuns também agrega as noções, atribuídas por Barthes (2015; 2009) à Fotografia, que são o studium e o punctum. Segundo este autor, o studium é definido por um "meio querer" ou por um "interesse vago", pela motivação ou por aquilo que desperta o gosto ou interesses gerais do Spectator por uma dada imagem (no nosso caso, pelo cartum). A noção de punctum, também segundo Barthes, contraria o studium, que é aspecto que está presente numa foto que nos fere, nos atinge, nos machuca e até nos atrai. Enquanto produção humana (e não a "reprodução do real", como ocorre com muitas fotografias) e de natureza um tanto diferente da fotografia, o cartum assume esta perspectiva de contradizer a realidade ou ao invés de apenas retratá-las? Uma foto apenas reproduz o mundo vivido? Será mesmo?

O filósofo Walter Benjamin diz-nos o seguinte sobre a Fotografia: "A natureza que fala à câmera é diferente da que fala aos olhos. Diferente sobretudo porque a um espaço conscientemente explorado pelo homem se substitui um espaço em que ele penetrou 
inconscientemente" (BENJAMIN, 2017, p.55). Este autor salienta a importância do trabalho realizado por August Sander ${ }^{4}$ (que teve a obra rejeitada pelos nazistas, pois não representava o ideal ariano) na construção de um corpus que revela a natureza humana proveniente das mais diferentes camadas sociais. A fotografia nos permitiu ver coisas que não são visíveis a olho nu (permitiu significativos avanços nas ciências), coisas de que não tínhamos notado no mundo exterior micro e macroscópico que foram enquadradas, fotografadas, reduzidas, ampliadas, registradas, colecionadas e contempladas. Contudo, ao selecionar determinado aspecto (ou enquadramento) e, não outros, "é atribuir importância" (SONTAG, 2004, p.41) de algo digno de permanecer para a posteridade. Neste sentido, uma fotografia é sempre arbitrária.

A Fotografia, enquanto reprodução da realidade - fragmentação do real vivido, não traz em si mesma um conhecimento sobre o que foi retratado. Um exemplo disto é a visão das fotografias das indústrias alemãs $A E G^{5}$ e $\mathrm{Krupp}^{6}$, que são mencionadas tanto por Sontag quanto por Benjamin em referência a Bertold Brecht: quem as vê não supõe o peso histórico que carregam. Assim, uma imagem que retrata o mundo real pode não permitir 0 estabelecimento de relações e gerar conhecimento, exceto a partir daquilo que conhecemos e compreendemos do mundo. Benjamin (2017) finaliza seu texto elaborando alguns questionamentos: a fotografia estará fadada a uma legenda ${ }^{7}$ que a explique? E recorda Baudelaire ao dizer que, os analfabetos contemporâneos não serão os iletrados, mas aqueles que não sabem ler uma fotografia.

Gillian Rose (2002) diz-nos que atualmente acessamos imagens de muitas formas diferentes, contudo, uma imagem nunca é inofensiva tampouco inocente, não se tratam de janelas transparentes para o mundo real, elas o exibem e o recortam de modos e maneiras bem específicas.

Retomando, os objetivos deste trabalho foram: (a) investigar e apresentar concepções de professores em formação acerca de um cartum publicado em suplemento da Revista Ciência Hoje das Crianças voltado ao público infanto-juvenil e (b) apresentar uma análise semiológica estrutural de elementos imagéticos constante do mesmo cartum a partir do referencial teórico barthesiano.

\section{Metodologia}

Organizamos este trabalho em duas partes principais. O estudo I trata de uma análise imagética do cartum, assim como proposta pelas autoras Campos et al (2008). O estudo II trata da análise de concepções de graduandos e graduados de um curso de licenciatura em ciências biológicas sobre um cartum publicado pela Sociedade Brasileira para o Progresso da Ciência (SBPC), como suplemento à Revista Ciência Hoje das Crianças (CHC). A análise de dados do Estudo II foi mediante a proposta de Análise Textual Discursiva, doravante, ATD

\footnotetext{
${ }^{4}$ Ver, por exemplo, em web: http://www.tate.org.uk/art/artists/august-sander-5319_acesso em 30.01.2018.

${ }^{5}$ Indústrias AEG, https://en.wikiarquitectura.com/building/aeg-turbine-factory/\#lg=1\&slide=1, acesso em 18.01.2018.

${ }^{6}$ Indústrias Krupp em web: https://images.fineartamerica.com/images-medium-large/germany-kruppsteelworks-granger.jpg, acesso em 18.01.2018.

${ }^{7}$ Como lembra Barthes (2015) em seu texto "Mensagem Fotográfica" em O obvio e o Obtuso, a palavra é parasita da imagem.
} 
(MORAES, GALIAZZI, 2016; 2006). Esta modalidade de análise de dados qualitativos subdivide-se em duas categorias unitarizadas, a saber, a análise de conteúdo e a análise de discurso. Assim, a ATD trata-se de processo que começa com a chamada unitarização, tratase de processo no qual os textos são apartados em unidades de significação. Tais unidades podem gerar "outros conjuntos de unidades oriundas da interlocução empírica, da interlocução teórica e das interpretações feitas pelo pesquisador" (MORAES; GALIAZZI, 2006, p. 118). Para estes autores, trata-se de um contínuo movimento interpretativo do significado pelo pesquisador, no qual ele próprio apropria-se de outras vozes e palavras num verdadeiro esforço interpretativo para mais bem compreender o texto.

\section{Estudo I: a mensagem imagética do Cartum}

A Figura 1 indica o contexto integral da página do suplemente da $\mathrm{CHC}$ do qual o cartum utilizado neste trabalho fora extraído. Quais são as possíveis mensagens transmitidas pelos cartuns selecionados neste estudo? Iniciaremos nossa análise da conforme apresentada por Campos et al (2008), isto é, análise sintagmática com análises denotativas e conotativas de categorias do cartum como, por exemplo, o traço, personagens, símbolos, ambiente, linguagem corporal, elementos da história em quadrinhos e, por fim, o plano da imagem, que em conjunto buscam compreender as unidades de significados constantes da Figura 2. Ao tomarmos a Figura 2 para uma análise sintagmática dividiremos a mensagem imagética em unidades sintagmáticas buscando compreender a mensagem existente. $O$ menino possui um balão de fala o qual apresenta estrelas, duas maiores e uma menor. $O$ balão de fala é um recurso comum nas histórias em quadrinhos ou HQ's. Quando, por exemplo, um balão de fala traz símbolos como cobras, lagartos, explosivos, caveiras, hashtag, ossos, etc. remetem a palavras de baixo calão. E, da mesma maneira, também a expressão "Dizer cobras e lagartos", como lembra Campos et al (2008), referem-se a ofensas verbais.

Ao compreender o fragmento do cartum da Figura 2 como uma unidade sintagmática, pode-se compreender que relação da criança sentada numa cadeira para com a mulher abaixada (quase ajoelhada) é de complementaridade, pois há uma relação entre ambos cuidadora e o paciente. Tal relação é ampliada se considerarmos a agitação do menino ou da criança - seus olhos arregalados, a movimentação do corpo e a boca aberta - que contrasta com a tranquilidade da mulher - representada no cartum com os olhos com pálpebras semicerradas, tem seu olhar em direção ao menino, os traços que indicam movimento na mulher estão apenas em volta do movimento que ela faz com a gaze em volta do dedo do menino e ela sorri. Na situação apresentada, a criança diz "estrelas", possivelmente referindo-se à dor, em seu balão de fala e aponta com o indicador o seu joelho. A mulher sorri e enrola o que parece ser uma gaze ou compressa no dedão do menino. Da cabeça do menino saem riscos de tamanhos diferentes e há outros elementos utilizados no cartum e em linguagem de história em quadrinhos. Um exemplo disto são os traços que indicam movimento em volta do corpo de ambos, as chamadas 'linhas cinéticas'.

Retomando, no que se refere à linguagem corporal, em sua dimensão denotativa, vê-se na Figura 2 um menino e uma mulher, um de frente para o outro. Um primeiro signo no que se refere à leitura de proporção entre os corpos. O menino está sentado numa cadeira com apoio de um de seus pés, usa bermuda e camiseta e, pelos traços do desenho, é branco. Está descalço e abaixo da cadeira onde está sentado há uma sandália (chinelo). Abaixo da cadeira é exibido o que parecer ser uma caixa de medicamentos (há uma cruz estampada na caixa). 
Sobre a caixa há uma tesoura e ao lado dela um vidro que parece de medicamento (há um rótulo sem dizeres). Também pelo traço, vê-se que a mulher é branca e usa camiseta regata, bermuda, calçado fechado, tiara e brincos redondos na orelha. Os cabelos são na altura do queixo. Em suas mãos, ela tem uma gaze ou rolo de esparadrapo. Ela segura com sua mão direita o pé direito do menino e sorri. É possível que o leitor da CHC perceba (na conotação perceptiva) que a mulher agiu corretamente ao ajudar a criança e por esta razão ela sorri. Os olhos da mulher com pálpebras semicerradas podem transmitir ao leitor a tranquilidade, já mencionada, de quem está a tratar do problema apontado pela criança. A reação da mulher, em relação ao exagero dos traços na criança - boca e olhos arregalados, estrelas no balão de fala, o dedo indicador que aponta o joelho e a outra mão "apertando" o assento da cadeira -, também faz transparecer que há um exagero ou excesso da reação da criança diante do ferimento.

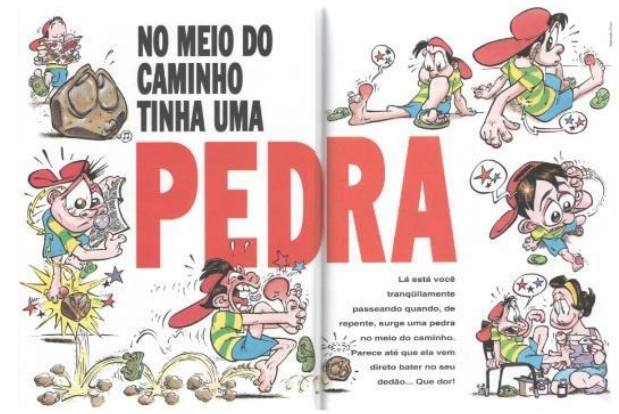

Figura 1 - Contexto da página de onde o cartum foi extraído. Fonte: SBPC. Sociedade Brasileira para o Progresso da Ciência. CIENCIA HOJE NA ESCOLA 3: Corpo Humano de Saúde. 6. a Edição, Rio de Janeiro: Ciência Hoje, 2006, p.38-39.

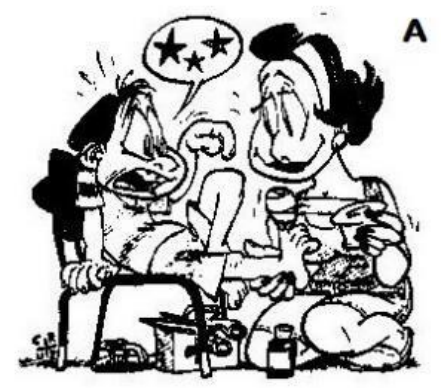

Figura 2 - Detalhe do cartum do suplemento da Revista Ciência Hoje das Crianças utilizado na parte Il deste estudo. llustrador Cruz, CHC 2006.

O plano de enquadramento da Figura 2 é o de corpo inteiro do cartum, assim, tanto o menino quanto à mulher aparecem de corpo inteiro na imagem, o que pode evocar um distanciamento do leitor com a cena. Já o plano e enquadramento que potencializa o corte da imagem de meio busto para a maioria dos integrantes ou somente o close up da cabeça indica proximidade e até intimidade com o leitor, como já mencionado (BELLS, 2004; 2001). Tais aspectos visuais utilizados no cartum podem aumentar ou reduzir as distâncias entre o que é retratado (neste caso, cartunizado) e o leitor da CHC. Os planos evocados tantos na Figura 2 possuem signos, como bem relembra Barthes (2009; 1986), não estão evidentes na linguagem do cartum, mas representam algo que não está lá de forma explícita. Um olhar, uma boca, um acidente.

Os elementos de fácil decodificação estão presentes nos cartuns da Figura 2. Eles são: as estrelas no balão de fala, a agitação presente na forma dos elementos gráficos em torno do 
menino, os olhos arregalados ou semicerrados, o sorriso, o vidro de remédios, o rolo de esparadrapo ou gaze, a tesoura, a cruz na caixa de primeiros socorros, a indumentária de ambos, a cadeira e o olhar em direção de quem está machucado. O que indica que é um menino na cena? Pensando que os cartunistas trabalham com estereótipos, um menino é quase sempre retratado assim: cabelos curtos, a bermuda, camiseta e a proporção de seu corpo em relação à mulher (GOMES, SIQUEIRA, CODATO, 2019). E o que indica que se trata de uma mulher adulta: a proporção corporal em relação ao menino, os brincos, as mamas salientes, o corte de cabelo e a massa corporal. O traçado do desenho é o cartum, tipo de representação visual que exagera em determinadas característica e elimina determinados detalhes (EISNER, 1999 apud CAMPOS et al, 2008) o que pode sim facilitar a compreensão e a leitura da imagem. $O$ exagero da presença de signos nos desenhos apresentados, como bem apontou Barthes (2009; 1986), pode subestimar a capacidade cognitiva ou intelectiva do leitor na decodificação dos mesmos. O processo de identificação, do leitor da CHC com os cartuns da Figura 2 acima apresentada, faz com que estes leitores reconheçam-se enquanto crianças e adolescentes nas representações visuais apresentadas. O ambiente da Figura 2 são, como em todo cartum, extremamente simplificados (CAMPOS et al, 2008), praticamente inexistem elementos no cenário que indiquem qualquer forma de composição deste.

\section{Estudo II: Lendo e analisando Cartuns da CHC: a visão de graduandos de ciências biológicas}

Participaram desta segunda etapa do estudo vinte graduandos e graduandas do Curso de Licenciatura e Bacharelado em Ciências Biológicas. As idades variaram entre 19 e 27 anos de idade. Os participantes responderam por escrito algumas questões de um roteiro prédefinido na presença do pesquisador. O roteiro integrou, na ocasião da coleta de dados, parte de uma seleção para uma bolsa de extensão universitária da mesma universidade na qual estão regularmente matriculados no início de 2018. O roteiro, em linhas gerais, solicitava que os participantes: indicassem as motivações pessoais para participar do projeto, realizassem a análise de um dos cartuns apresentados. Os dados deste trabalho referem-se aos estudantes que escolheram a Figura 2. E que, por fim, reelaborassem um trecho de um parágrafo do artigo "A mensagem fotográfica"8 de Roland Barthes (2015). Do roteiro aplicado aos rapazes e moças, licenciandos e licenciados, do curso de ciências biológicas, fizemos o recorte de apenas uma das questões, que é apresentada a seguir: "Escolha apenas uma das imagens abaixo. Observe-a com atenção e, em seguida, faça uma análise dela". (Orientações constantes do roteiro para análise das figuras pelos graduandos). Vale salientar que os cartuns utilizados neste estudo são partes integrantes de outros contextos maiores e que não foram inseridos em sua totalidade no instrumento de coleta de dados, pois desvirtuaria a proposta inicial, isto é, compreender se os cartuns veiculados pela CHC na divulgação científica - aqui compreendidos como análogos à fotografia, enquanto produção humana, como propõe Barthes (2015), Joly (2005) e Sontag (2004) - poderiam ser interpretados por estudantes do curso de ciências biológicas e quais recortes seriam produzidos pelo "olhar" do professor e da professora de biologia e ciências em formação?

\footnotetext{
${ }^{8}$ Constante do livro BARTHES, Roland, 1915-1980. A mensagem fotográfica. O óbvio e o obtuso. Lisboa: Edições 70, 2015. p. 11-26.
} 


\section{Sobre a Figura 2}

Quando olhamos para uma imagem, neste caso, um cartum, realizamos constantemente interpretações a luz de nossa história pessoal enquanto aprendizes e do que e de quem somos culturalmente, isto é, de quanta cultura nos apropriamos ao longo da formação humana, aprendida de modo solitário ou com a mediação de outrem (BARTHES, 2009). De fato, é a partir desta história de vida bastante peculiar que será possível perceber ou não determinados aspectos presentes no signo fotográfico (ou mesmo no cartum, neste caso). Para a Figura 2, acima apresentada, selecionamos cinco fragmentos de análise de estudantes ${ }^{*}$ ) todos e todas de nomes fictícios. Jeferson é o único participante/respondente do sexo masculino e é negro e fez uma série de apontamentos em suas análises do cartum apresentado (ver Figura 2). Para ele,

"[...] Na figura temos uma criança com o dedão do pé machucado e possivelmente uma mãe fazendo um curativo. Embora seja uma figura em preto e branco, fica clara a representação de pessoas brancas, além disso, a mãe parece bastante o estereótipo de 'dona de casa ideal' das últimas décadas do século XX. Onde é comum vermos em filmes e novelas, principalmente norte-americanos, com donas de casa perfeitamente bem cuidadas, em roupas curtas/sensuais, felizes com afazeres domésticos e algo quentinho no forno a espera do marido que chega do trabalho. [...] Além disso, é pouco comum a representação de homens em afazeres domésticos ou de cuidados com os filhos. Geralmente, a figura do cuidado é atribuída a mulher, reservando ao homem as representações de trabalho, proteção e força, já que na sociedade, ele é frequentemente tido como o provedor, enquanto a mulher, o papel de cuidadora, mantenedora da educação e cuidado do lar" (Jeferson*, negro, 23 anos de idade, licenciado/bacharelando).

O participante Jeferson fez uma leitura para além dos signos ausentes da figura. Ele considerou ao mesmo tempo o "que está posto em cena" ou o "Conteúdo Manifesto" do cartum, mas fez uma leitura que considerou outros aspectos que remetem à histórica submissão feminina ao masculino e os papéis social e historicamente definidos. Ele destacou ainda aspectos do apagamento cultural e étnico da cultura negra (NASCIMENTO, 2016; OLIVEIRA NEVES, 2012). Por fim, suas análises ultrapassaram o conteúdo expresso no cartum e avançaram para o chamado "Conteúdo Latente" (BANKS, 2009; ROSE, 2002). As demais participantes de nossa amostra são do sexo feminino e realizaram algumas observações e recortes bem pessoais do cartum da Figura 2.

"A imagem é composta por uma criança, esta se encontra com um ferimento no pé e uma figura feminina, possivelmente materna, que cuida do ferimento e transmite um olhar calmo e acalentador envolvendo a atmosfera da figura" (Maristela*, branca, 20 anos de idade, $2 .^{\circ}$ ano).

"[...] observa-se uma garota que machucou o seu pé e uma mulher, a qual parece ser sua mãe e está ajudando-a com seu ferimento. Nota-se que a menina parece assustada e com dor, mas a mulher está calma e paciente, com olhar de cuidado e carinho como quem diz: 'tudo bem, eu estou aqui e vou cuidar de você'. Percebe-se que a mulher possui uma caixa de primeiros socorros e já está cuidando do pé da criança" (Mônica*, branca, 19 anos, $2 .^{\circ}$ ano). 
"[...] podemos observar uma criança que se machucou e está sendo tratada por uma figura feminina que, pela demonstração de ternura, não apenas na atitude de cuidar, mas no afeto ilustrado em sua face, podemos notar uma ligação familiar ou até escolar, como uma professora. [...] é um evento cotidiano a uma criança e a paciência e a ternura devem ser incentivadas" (Júlia*, branca, 21 anos, 3. ano).

"[...] retrata uma criança com sua mãe, provavelmente esta se machucou com alguma de suas brincadeiras e sua mãe está fazendo um curativo. A criança está preocupada com a possibilidade de doer mais o machucado na hora de fazer o curativo" (Alessandra*, parda, 22 anos, 5. ${ }^{\circ}$ ano).

Assim como o estudante Jeferson, as licenciandas em ciências biológicas reconheceram e decodificaram inúmeros elementos do cartum apresentado. Entretanto e, diferentemente de Jeferson, elas se reconheceram enquanto integrantes étnicas e de gênero sexual da figura ou ao menos não fizeram quaisquer apontamentos neste sentido. Três delas são brancas e uma é parda. Todas as estudantes tem pouca diferença de idade, mas redigiram recortes distintos do cartum observado. As estudantes Júlia, Mônica e Maristela reconheceram elementos do chamado Conteúdo Manifesto do cartum, sendo que foi Maristela quem mais fez uma descrição neste sentido: transformar a imagem em texto, e assim, acaba sendo um discurso sobre a imagem (BARTHES, 2009). Possivelmente a participante Mônica confundiu o boné vermelho, que é perfeitamente reconhecível na Figura 1 colorida, com cabelos compridos - outro estereótipo do gênero feminino presente nos cartuns (GOMES, SIQUEIRA, CODATO, 2019) - no encosto da cadeira ou fez uma leitura distinta dos demais. O Conteúdo Latente na leitura feita pelas estudantes à Figura 2 remetem à compreensão do papel feminino (na sociedade) expressa no cartum: à calma, ao aconchego, à maternidade, à paciência, ao carinho, à ternura, à ajuda ao outro, à relação entre mãe e filho ou filha e ao cuidado com o outro. Seriam estes atributos do feminino entre as licenciandas do curso de Ciências Biológicas? Há a possibilidade de uma dada leitura manifestar-se em termos de uma conotação abusiva como propõe Barthes (2015)? O relato de Alessandra enquadra-se nesta modalidade quando vê o que não está lá quando diz: que por ser criança "esta se machucou com alguma de suas brincadeiras" ou que crianças sempre brincam e sempre se machucam porque brincam? Ou seria também uma conotação abusiva quando menciona que "A criança está preocupada com a possibilidade de doer mais o machucado na hora de fazer o curativo"? As linhas cinéticas denotam movimento, mas de quê?

\section{Considerações finais}

Neste estudo propomos a análise semiológica estrutural de elementos imagéticos de um cartum publicado por um suplemento da Revista Ciência Hoje das Crianças e compreender como graduandos do curso de Licenciatura em Ciências Biológicas interpretam e analisam o mesmo cartum. Nossas análises sugerem que os estudantes elaboram recortes "bem particulares" ou até peculiares da imagem que observam, que em nosso caso se tratou de um cartum de uma revista de divulgação científica. Estas leituras, em muitos casos, mostraram-se em extremos - ou exclusivamente descrevendo-se o que se vê, literalmente e mesmo assim fazem uso "inconsciente" de signos e da leitura destes. E, no outro polo, atribuem-se exageradamente atributos e realizam leituras do que não está efetivamente lá 
ou como Barthes (2015) sugere, propõe conotações abusivas da imagem lida. Por fim, acreditamos que os cursos de formação inicial de professores necessitam investir ou preocupar-se com estratégias que de alguma maneira possibilitem ou garantam a Alfabetização Midiática e Informacional (AMI), como proposto pela UNESCO (2013), para que professores e professoras em formação inicial tenham uma compreensão semiótica das imagens utilizadas em sala de aula, imagens que estão presentes nos livros didáticos adotados, nas apostilas, nos filmes (extraídos ou não do youtube), nas fotografias exibidas ou utilizadas na "exposição de slides", etc. e ainda de possíveis releituras que estes próprios estudantes (graduandos e graduandas) possam produzir acerca do texto científico, em imagens que de alguma forma retrate - de forma democrática - a população brasileira em sua completude e pluralidades.

\section{Agradecimentos}

Os autores agradecem o financiamento da pesquisa pela Coordenação de Aperfeiçoamento de Pessoal de Nível Superior (CAPES). Publicação decorrente do pósdoutorado do primeiro autor (Edital PNPD/CAPES).

\section{Referências}

BANKS, M. Dados visuais para a pesquisa qualitativa. Porto Alegre: ArtMed, 2009. 176p.

BARBOSA, G. G.; RABAÇA, C.A.; Dicionário de comunicação. São Paulo: Ática. 1998.

BARTHES, Roland. O óbvio e o obtuso. Lisboa: Edições 70, 2015.

BARTHES, Roland. A aventura semiológica, São Paulo: Martins Fontes, 2001.

BARTHES, Roland. A Câmera Clara, Porto: Edições 70, 2010.

BARTHES, Roland. Elementos de Semiologia, Porto: Edições 70, 2005.

BARTHES, Roland. Inéditos. Imagem e Moda - Volume 3, São Paulo: Martins Fontes, 2005.

BARTHES, Roland. O sistema da moda, São Paulo: Martins Fontes, 2009.

BARTHES, Roland. Le texte et l'image. [Paris], Pavillon des arts, 7 mai-3 août, 1986. [Paris]

BELL, Philip. Content analysis of visual images. In: VAN LEEUWEN, Theo \& JEWITT, Carey. The handbook of visual analysis (pp. 10-34). London: SAGE Publications Ltd., 2004.

BENJAMIN, Walter. Estética e sociologia da arte. Belo Horizonte: Autêntica Editora, 2017.

BNCC. Base Nacional Curricular Comum. Ministério da Educação, 2017. http://basenacionalcomum.mec.gov.br/images/BNCC_20dez_site.pdf Acesso em 20.01.2018.

CAMPOS, Maria Teresa Cardoso de. O homem é um animal que cria códigos. E-COM (Belo Horizonte), v. 2, p. 1-3, 2008.

CAMPOS, Maria Teresa Cardoso de; SALLES, Vanessa Madrona Moreira; FONSECA, Marília Lima; FIGUEIREDO, Daniel Fortes de. Argumentação ética: campanha educativa do Jornal do ônibus. Revista de Estudos da Comunicação, v. 10, p. 85-90, 2009. 
CAMPOS, Maria Teresa Cardoso de; SALLES, Vanessa Madrona Moreira; FONSECA, Marília Lima; FIGUEIREDO, Daniel Fortes de. Uma leitura semiológica: campanha educativa do Jornal do Ônibus. E-COM (Belo Horizonte), v. 2, p. 1 n.5, 2009.

CARVALHO, A. M. P.; GIL-PÉREZ, D. Formação de professores de ciências: tendências e inovações. São Paulo: Cortez Editora, 2001.

COELHO DE SOUZA, Marcela. A vida material das coisas intangíveis. Em: Conhecimento e cultura: práticas de transformação no mundo indígena. pp.97-118. Brasília: Athalaia, 2010.

CORRÊA, Mariana Rocha Amarante. Divulgação científica na internet: um estudo de caso sobre a Ciência Hoje das Crianças Online. 2015. 148p. Dissertação de Mestrado. (Mestre em Ensino em Biociências e Saúde). Instituto Oswaldo Cruz. Rio de Janeiro.

GOMES, Paulo César. SIQUEIRA, Alexandra Bujokas de. CODATO, Marcos Vinicius. "O C de colonizador é análogo ao C de cartum?": uma análise de cartuns presentes na seção curiosidades da revista Ciência Hoje das crianças. Revista Eletrônica de Educação, v. 13, n. 3, p. 1058-1081, 2019.

GOUVÊA, Guaracira. A Divulgação Científica para Crianças: O caso da Ciência Hoje das Crianças. 2000. p.305. Tese (Doutorado em Educação Gestão e Difusão Em Biociências). Universidade Federal Fluminense. Rio de Janeiro, 2000.

GOUVÊA, Guaracira. A revista Ciência Hoje das Crianças e práticas de leituras do público infantil. Em: MASSARANI, L. (Organiz.) O pequeno cientista amador: a divulgação científica e o público infantil. Rio de Janeiro: Vieira e Lent. 2005. p. 47-57.

GOUVÊA, Guaracira. Redes cotidianas e os museus de ciências. Parcerias Estratégicas. Brasília, n. 11, p.169-174, 2001.

JOLY, Martine. A imagem e os signos. Lisboa: Edições 70, 2005.

LEAL P.H.; REALI, A.M.M.R.; Indicadores de desenvolvimento profissional da docência: construção, avaliação e usos. Est. Aval. Educ., São Paulo, v. 26, n. 61, p. 82-122, jan./abr. 2015.

MASSARANI, Luísa. Reflexões sobre a divulgação científica para crianças. Em: Congresso Brasileiro de Ciências da Comunicação, 22, 1999. Rio de Janeiro. Anais... Rio de Janeiro: Intercom, p.1-5, 1999.

MEC. Ministério de Educação e Cultura. Parâmetros curriculares nacionais: ciências naturais / Secretaria de Educação Fundamental. - Brasília : MEC/SEF, 1998b.

MEC. Ministério de Educação e Cultura. Parâmetros Curriculares Nacionais: Introdução aos Parâmetros Curriculares Nacionais. Secretaria de Educação Fundamental. - Brasília: MEC/SEF, 126p. 1998a.

MORAES, R. Uma tempestade de luz: a compreensão possibilitada pela análise textual discursiva. Ciência \& Educação, v. 9, n. 2, p. 191-210, 2003.

MORAES, R.; GALIAZZI, M.C. Análise textual discursiva: processo reconstrutivo de múltiplas faces. Ciência \& Educação, v. 12, n. 1, p. 117-128, 2006.

MORAES, R.; GALIAZZI, M.C. Análise Textual Discursiva. Ijuí: Editora Unijuí, 2016, 264p.

NASCIMENTO, Abdias do. O genocídio do negro brasileiro: processo de um racismo mascarado. São Paulo: Perspectiva, [1978] 2016. 
OLÍMPIO. Ana Filipa Pereira Miguel. Uma caricatura de país. (Mestrado em Desenho). 2013. Universidade de Lisboa. Faculdade de Belas Artes.

OLIVEIRA NEVES, Lino João de. Volta ao começo: demarcação emancipatória de terras indígenas no Brasil. Universidade de Coimbra, 2012. Tese.

PEREIRA, Ana Rita Rodrigues. C de capitalismo é análogo do C de cartoon: uma análise de conteúdo de cartoons. 2015. Dissertação de Mestrado. (Mestrado em Sociologia). Universidade do Porto. 196p. Universidade do Porto - UP. Porto, Portugal, 2015.

POZO, J. I.; CRESPO, M. A. G. A aprendizagem e o ensino de ciências: do conhecimento cotidiano ao conhecimento científico. 5. ed. Porto Alegre: Artmed, 2009.

ROSE, Gillian. Visual methodologies: An Introduction to the Interpretation of visual materials. London: SAGE, 2002. 229p.

SANTOS, I. A. dos. A responsabilidade da escola na eliminação do preconceito racial: alguns caminhos. In: CAVALLEIRO, E. (Org.). Racismo e anti-racismo na educação. São Paulo: Summus, 2001. p. 97-114.

SHAW, M Matthew J. Drawing on the collections. Journalism Studies, 8 (5), 742-754. 2007.

SIQUEIRA, Alexandra Bujokas de. Mídia-educação na formação de professores: a experiência da Universidade Federal do Triângulo Mineiro a partir da proposta da UNESCO. Em: ELEÁ, I. (Ed.) Agentes e Vozes: um Panorama da Mídia-Educação no Brasil, Portugal e Espanha. Suécia: The International Clearinghouse on Children, Youth and Media, 2014. http://www.nordicom.gu.se/sites/default/files/publikationer-hela-pdf/yearbook_2014.pdf.

Acesso em: 05.02.2018.

SONTAG, Susan. Sobre fotografia. São Paulo: Companhia da Letras, 2004.

UNESCO. WILSON, C. et al. Alfabetização Midiática e Informacional: currículo para a formação de professores, Brasília: UNESCO, UFTM, 2013.

XAVIER, Caco. Aids é coisa séria! - humor e saúde: análise dos cartuns inscritos na I Bienal Internacional de Humor, 1997. Hist. Cienc. Saude - Manguinhos, Rio de Janeiro, v.8, n.1, pp.193-221, Junho, 2001. 